\title{
Placental cell fates are regulated in vivo by HIF-mediated hypoxia responses
}

\author{
David M. Adelman, ${ }^{1,2}$ Marina Gertsenstein, ${ }^{3}$ Andras Nagy, ${ }^{3}$ M. Celeste Simon,,${ }^{2,4,5}$ and Emin Maltepe ${ }^{1}$ \\ ${ }^{1}$ Department of Pathology, University of Chicago, Chicago, Illinois 60637, USA; ${ }^{2}$ Abramson Family Cancer Research \\ Institute, University of Pennsylvania School of Medicine, Philadelphia, Pennsylvania 19104, USA; ${ }^{3}$ Samuel Lunenfeld \\ Research Institute, Mount Sinai Hospital, Toronto M5G 1X5, Canada; ${ }^{4}$ Department of Cell and Developmental Biology \\ and the Howard Hughes Medical Institute, University of Pennsylvania School of Medicine, Philadelphia, \\ Pennsylvania 19104, USA
}

Placental development is profoundly influenced by oxygen $\left(\mathrm{O}_{2}\right)$ tension. Human cytotrophoblasts proliferate in vitro under low $\mathrm{O}_{2}$ conditions but differentiate at higher $\mathrm{O}_{2}$ levels, mimicking the developmental transition they undergo as they invade the placental bed to establish the maternal-fetal circulation in vivo. Hypoxia-inducible factor-1 (HIF-1), consisting of HIF-1 $\alpha$ and ARNT subunits, activates many genes involved in the cellular and organismal response to $\mathrm{O}_{2}$ deprivation. Analysis of Arnt $^{-/-}$placentas reveals an aberrant cellular architecture due to altered cell fate determination of Arnt $^{-/-}$trophoblasts. Specifically, Arnt ${ }^{-/-}$ placentas show greatly reduced labyrinthine and spongiotrophoblast layers, and increased numbers of giant cells. We further show that hypoxia promotes the in vitro differentiation of trophoblast stem cells into spongiotrophoblasts as opposed to giant cells. Our results clearly establish that $\mathrm{O}_{2}$ levels regulate cell fate determination in vivo and that HIF is essential for mammalian placentation. The unique placental phenotype of Arnt $^{-/-}$animals also provides an important tool for studying the disease of preeclampsia. Interestingly, aggregation of Arnt $^{-/-}$embryonic stem (ES) cells with tetraploid wild-type embryos rescues their placental defects; however, these embryos still die from yolk sac vascular and cardiac defects.

[Key Words: HIF; ARNT; hypoxia; placenta; trophoblast; stem cell]

Received July 3, 2000; revised version accepted November 3, 2000.

The heart, blood, and vascular network constitute the first functional organ system to be generated in a mouse conceptus. Prior to E9.5, the embryo resides in a low $\mathrm{O}_{2}$ environment (Mitchell and Yochim 1968; Fischer and Bavister 1993) and relies primarily on glycolysis to satisfy its metabolic needs (Akazawa et al. 1994). Establishment of placental circulation by E9.0-E9.5 permits $\mathrm{O}_{2}$ and nutrient delivery through the fetal vasculature to the rapidly growing embryo. Formation of placental and embryonic circulatory systems is regulated by the coordinated action of fundamental genetic and physiologic factors (Maltepe et al. 1997).

Oxygen acts as a potent regulator of vascular development. Endothelial cells (Phillips et al. 1995) and hematopoietic progenitors (Adelman et al. 1999) proliferate in response to low $\mathrm{O}_{2}$. Human placental cells also proliferate during hypoxic culture conditions, but high $\mathrm{O}_{2}$ levels inhibit proliferation and promote differentiation (Genbacev et al. 1997; Caniggia et al. 2000). The murine placenta is essentially composed of three distinct cell populations: labyrinthine trophoblasts, spongiotrophoblasts,

${ }^{5}$ Corresponding author.

E-MAIL celeste2@mail.med.upenn.edu; FAX (215) 746-5511.

Article and publication are at www.genesdev.org/cgi/doi/10.1101/ $\operatorname{gad} .853700$. and trophoblast giant cells (Cross et al. 1994). The innermost labyrinthine layer consists of syncytial trophoblasts, which surround fetal blood vessels that invade the chorionic plate and interdigitate with maternal blood sinuses to enable gas and nutrient exchange. The outermost polyploid giant cells, derived from diploid trophoblasts in the ectoplacental cone, form the interface between maternal and embryonic tissues. Located between the labyrinthine and giant cell layers are diploid spongiotrophoblasts, homologous with cytotrophoblasts in humans.

Members of the bHLH transcription factor family (Mash2, Hand1, and Id2) appear to be critical for generating trophoblast cell types. For example, Mash2-deficient embryos die at E10.5 because of a complete absence of spongiotrophoblast cells and subsequent expansion of the giant cell population (Guillemot et al. 1994, 1995). In contrast, Hand1 ${ }^{-/-}$mice arrest at E7.5 because of a block in trophoblast giant cell differentiation and a smaller ectoplacental cone (Riley et al. 1998). Of note, Hand1 expression promotes differentiation of the Rcho-1 trophoblast cell line into giant cells (Cross et al. 1995) whereas Mash2 expression inhibits Rcho-1 differentiation (Kraut et al. 1998). Therefore, Mash2 and Hand1 act as opposing influences in trophoblast development. Finally, Id2, an 
HLH protein that inhibits bHLH protein activity (Sun et al. 1991), is essential for maintaining human cytotrophoblasts in an undifferentiated state (Janatpour et al. 2000).

The role of $\mathrm{O}_{2}$ tension in modulating proliferation and/or differentiation within the human placenta prompted us to investigate the importance of hypoxiainducible factor-1 (HIF-1) function in controlling this process. HIF-1 is a heterodimeric transcription factor composed of the bHLH-PAS proteins HIF- $1 \alpha$ and the arylhydrocarbon receptor nuclear translocator (ARNT). HIF-1 mediates the transcriptional response to $\mathrm{O}_{2}$ deprivation by binding to hypoxia response elements (HRE) within the promoters or enhancers of genes involved in glycolysis, glucose transport, erythropoiesis, and angiogenesis (Bunn and Poyton 1996; Wenger and Gassmann 1997). HIF-1 activity is critical for normal development; mouse embryos lacking functional HIF-1 complexes die on or before E10.5. Hif-1 $1 \alpha^{-/-}$embryos show developmental arrest by E9.0 with significant mesenchymal cell death and impaired vascular development (Iyer et al. 1998; Ryan et al. 1998). Arnt ${ }^{-/-}$animals die by E10.5, displaying deficiencies in yolk sac and/or placental vascularization (Kozak et al. 1997; Maltepe et al. 1997). Furthermore, Arnt ${ }^{-1-}$ yolk sacs show decreased numbers of multilineage hematopoietic progenitors (Adelman et al. 1999). HIF-1 activity is therefore essential for the proliferation, survival, and/or differentiation of multiple embryonic tissues.

Given the requirement for HIF-1 in transcriptional responses to hypoxia and its ability to regulate cell proliferation and apoptosis (An et al. 1998; Carmeliet et al. 1998; Ravi et al. 2000), we reasoned that HIF-1 $\alpha /$ ARNT dimers may be critical to placentation. In addition to the defect described for labyrinthine blood vessels (Kozak et al. 1997), we found that $A r n t^{-/-}$placentas show a profound decrease in diploid spongiotrophoblast cell numbers and an increase in the giant cell population. Similarly, Arnt ${ }^{+/+}$trophoblast stem (TS) cells derived from mouse blastocysts preferentially differentiated into spongiotrophoblasts, as opposed to trophoblast giant cells, when cultured under hypoxic conditions. Arnt ${ }^{-/-}$ TS cells, however, failed to produce spongiotrophoblasts in vitro. Arnt ${ }^{-/-}$placentas also expressed low levels of TGF 33 , recently shown to be downstream from HIF and involved in human placentation (Caniggia et al. 2000). These results show that hypoxia regulates placental development in a HIF-dependent fashion, in part by promoting the differentiation of spongiotrophoblasts from trophectoderm. Aggregation of $\mathrm{Arnt}^{-/-}$ES cells with tetraploid wild-type embryos rescued the placental defect, but these tetraploid embryo $\Leftrightarrow$ ES cell chimeras still showed abnormal yolk sac blood vessels and a novel cardiac defect. Taken together, our results support a role for $\mathrm{O}_{2}$ as a novel determinant of placental cell fate, dependent on HIF function. Furthermore, Arnt ${ }^{-/-}$embryos show poor trophoblast invasion of maternal decidua, a phenotype similar to preeclamptic human placentas, and provide a unique model system for the study of this disease.

\section{Results}

Arnt $^{-/-}$placentas show impaired vascularization

Targeting of the murine Arnt locus has been described previously (Maltepe et al. 1997). We analyzed embryos from $\mathrm{Arnt}^{+/-} \times \mathrm{Arnt}^{+/-}$matings at E9.5 and detected severe impairment of placental vascularization in all Arnt $^{-/-}$embryos. Arnt ${ }^{+/+}$and Arnt ${ }^{+/-}$chorionic plates showed proper invasion by fetal vessels, leading to mature labyrinthine layers containing vascular beds full of primitive nucleated fetal erythroblasts, intermingled with vessels containing mature maternal erythrocytes (Fig. 1A,B). In striking contrast, Arnt ${ }^{-/-}$placentas contained no fetal vessels and were noticeably smaller, showing poor trophoblast invasion of maternal myometrium (Fig. 1C,D). Although chorioallantoic fusion occurred, Arnt ${ }^{-1}$ chorionic plates retained the compact structure characteristic of E8.5 placentas. Of note, the region normally occupied by spongiotrophoblasts contained large amounts of maternal blood and appeared to be composed primarily of trophoblast giant cells (Fig. 1D). E8.5 $\mathrm{Arnt}^{-/-}$placentas were also smaller than their wild-type or heterozygote counterparts, although no gross morphologic abnormalities were evident on examination of hematoxylin/eosin stained specimens (see Fig. 2A,B).

Arnt $^{-/-}$placentas show impaired spongiotrophoblast cell maintenance

To further examine the architecture of $A r n t^{-/-}$placentas, we analyzed $A r n t^{+/+}$and $A r n t^{-/-}$placentas by in situ hybridization for the presence of spongiotrophoblast and trophoblast giant cell populations. As shown in Figure 2, E8.5 $\mathrm{Arnt}^{-1-}$ placentas contained grossly comparable numbers of $4311^{+}$spongiotrophoblast and placental lactogen-1 (P1. Lac. $1^{+}$) trophoblast giant cells. The trophoblast giant cell layer, however, was less organized and did not form the sheetlike configuration surrounding the spongiotrophoblast layer and chorionic plate observed in $A r n t^{+/+}$placentas. In fact, Arnt $^{-/-}$placentas appeared to contain cells expressing both 4311 and Pl. Lac. 1 (see Fig. 2D,F). Mash2, a gene expressed primarily in diploid spongiotrophoblast cells and the chorionic plate /Guillemot et al. 1994), was also expressed at comparable levels in all placentas regardless of genotype (data not shown). Thus, establishment of all placental cell lineages occurs in the absence of ARNT expression. By E9.5, however, Arnt $^{-/-}$placentas contained almost no detectable $4311^{+}$ spongiotrophoblast cells, in contrast with $\mathrm{Arnt}^{+/+}$placentas (Fig. 3). When present, the spongiotrophoblast layer was reduced to small pockets of cells (Fig. 3F, arrow), whereas the $\mathrm{Pl}$. Lac. $1^{+}$giant cell population was greatly expanded. Of note, TGF 33 (a presumptive HIF-1 target gene in human placentas; Caniggia et al. 2000) was expressed at lower levels in E9.5 $\mathrm{Arnt}^{-{ }^{-}}$specimens compared with wild type (Fig. 3G, H).

To determine whether the decrease in spongiotrophoblasts was due to increased cell death, reduced prolifera- 


\section{Arnt $+/+$}
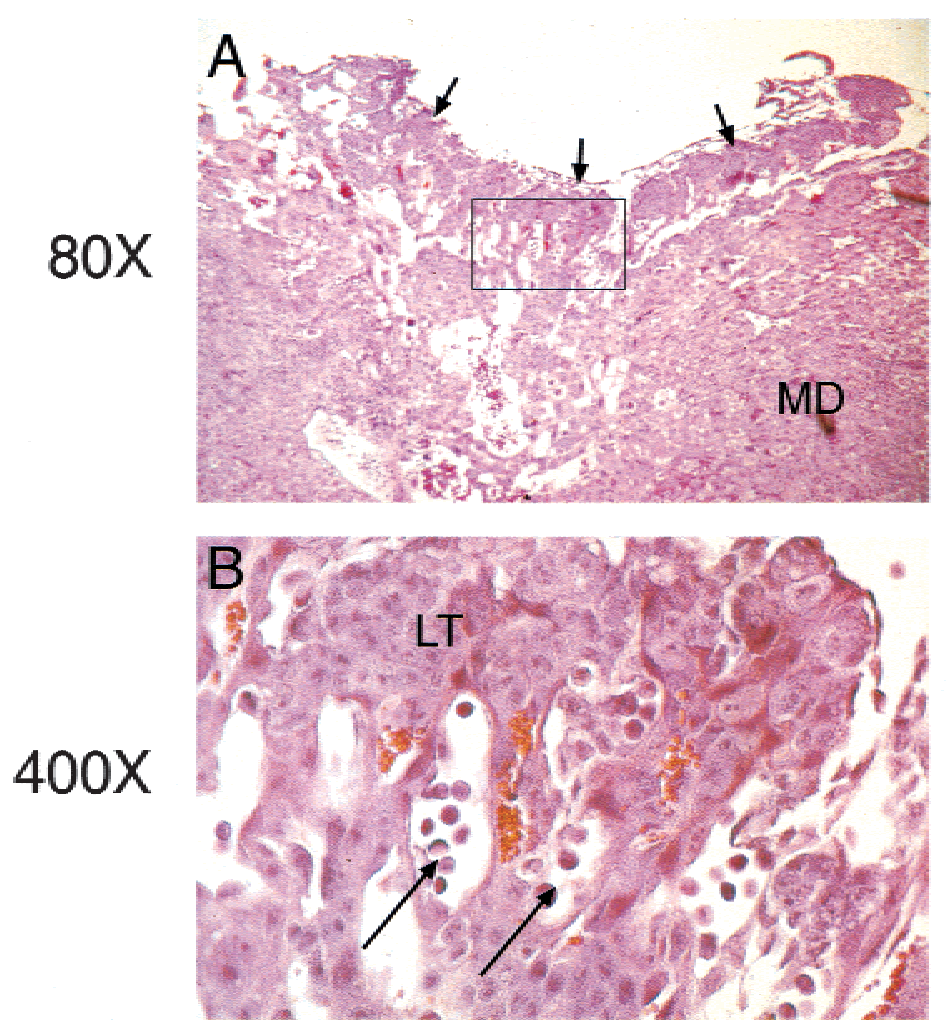

Arnt $-/-$
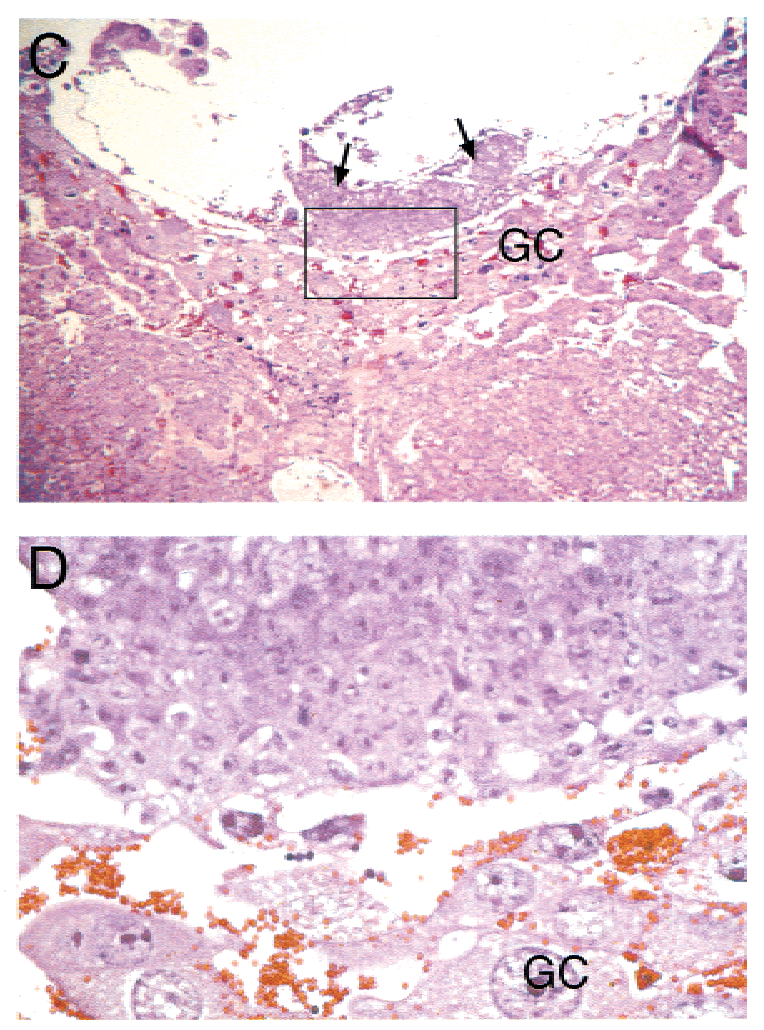

Figure 1. Vascular defects in E9.5 Arnt $t^{-/-}$placentas. H\&E-stained $A r n t^{+/+}(A, B)$ and $A r n t^{-/-}(C, D)$ sections showing the presence of a chorionic plate (short arrows in $A$ and $C$ ) in both animals, but lack of fetal vessels (long arrows in $B$ ) in the labyrinthine layer of the Arnt $^{-1-}$ placenta $(D)$. Original magnification in $A, C: 80 \times$; magnification of inset in $B, D: 400 \times$. (GC) Giant cells; (MD) maternal deciduum; (LT) labyrinthine trophoblast.

tion, or premature differentiation into other cell types, we subjected serial sections from $\mathrm{Arnt}^{+/+}$and $\mathrm{Arnt}^{-/-}$ placentas to TUNEL and Ki-67 immunohistochemistry. Wild-type E8.5 and E9.5 placentas showed relatively few TUNEL ${ }^{+}$cells, indicating a general lack of apoptotic cell death at this stage of development (data not shown). Arnt ${ }^{-/-}$placentas contained similarly few of $\mathrm{TUNEL}^{+}$cells showing that apoptosis does not account for the decrease in spongiotrophoblast number. Arnt ${ }^{+/+}$ and $A r n t^{-/}$placentas showed similar staining for Ki-67 (a marker used to assess cell proliferation) within the E8.5 spongiotrophoblasts and giant cells (Fig. 4A,B). Therefore, the proliferation of both $4311^{+}$ and Pl. Lac. $1^{+}$cells that occurs prior to E9.5 (Fig. 4C,D) is not affected in the absence of ARNT. We hypothesized that the defect of $\mathrm{Arnt}^{-/-}$placentas in maintaining a spongiotrophoblast population stems from an inability to prevent differentiation of diploid spongiotrophoblasts into giant cells. The evidence that placental cells express both 4311 and Pl. Lac.1 (see Fig. 2) suggests that placental cell fate is altered in Arnt $^{-/-}$ embryos.
Impaired placental vascularization is not intrinsic to $\mathrm{Arnt}^{-/-}$endothelium but secondary to disrupted placental development

We wished to determine whether the abnormal labyrinthine layer was intrinsic to a vascular endothelial defect in $\mathrm{Arnt}^{-/-}$embryos or secondary to an absence of placental factor(s) required for fetal blood vessel recruitment into the developing chorionic plate. Arnt ${ }^{-/-}$ES cells constitutively expressing $\beta$-galactosidase (LacZ) were injected into wild-type blastocysts, and chimeric animals were analyzed for LacZ expression within their placentas. ES cells contribute exclusively to epiblast derivatives and therefore are excluded from trophoblasts, extraembryonic visceral endoderm, and extraembryonic parietal endoderm (Nagy et al. 1990). The placenta, however, contains embryonic mesoderm derivatives (such as endothelial cells) in the labyrinthine layer that are ESderived (Tanaka et al. 1997). All remaining placental cell populations are derived from trophectodermal precursors (Nagy et al. 1990). As shown in Figure 4E, Arnt ${ }^{-/-}$endothelial cells were capable of invading the chorionic plate 


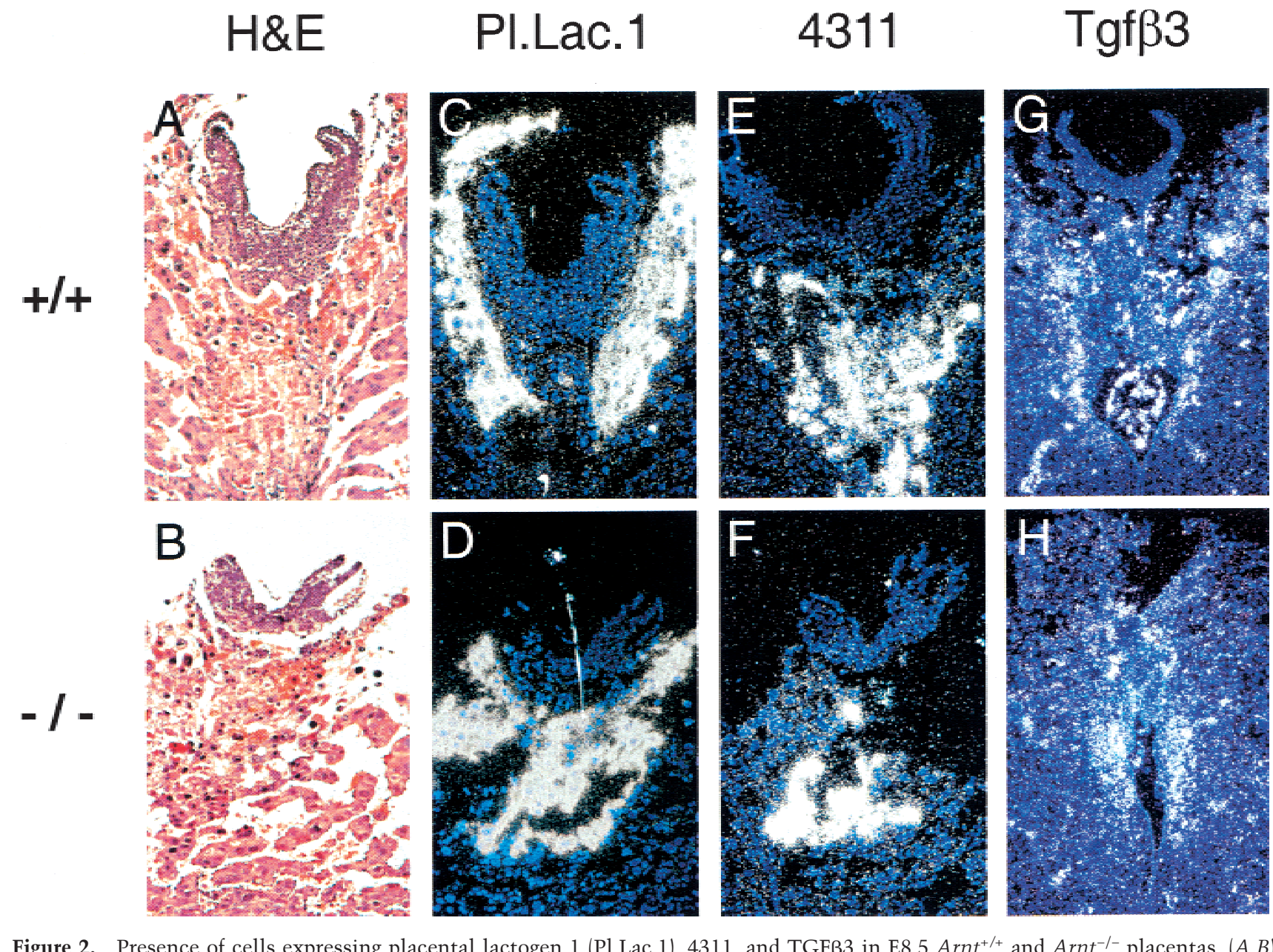

Figure 2. Presence of cells expressing placental lactogen 1 (Pl.Lac.1), 4311, and TGF 33 in E8.5 Arnt ${ }^{+/+}$and Arnt $t^{-/-}$placentas. $(A, B)$ hematoxylin- and eosin-stained sections from maternal tissues $\left(A r n t^{+/-}\right)$and placentas with the indicated genotypes. $(C-H)$ Adjacent sections analyzed via ${ }^{35} \mathrm{~S}$ in situ hybridization. Magnification, 100x.

and contributing to the labyrinthine layer of wild-type placentas. Therefore, the requirement for ARNT during placental vascularization is not intrinsic to allantoic endothelial cells. This finding was further supported by the normal placenta obtained by tetraploid embryo $\Leftrightarrow$ ES cell aggregation in which the embryo component was derived from $A r n t^{-/-}$ES cells (see below).

\section{Arnt $^{-/-}$trophoblast stem cells show proliferative} defects in vitro

Based on experiments performed with LacZ chimeras, defects observed in Arnt $^{-/-}$placentas appear to be intrinsic to placental cells. To better study Arnt $^{-/-}$trophoblasts, we derived TS cells from E3.5 blastocysts by using the method of Tanaka et al. (1998). Two independent $\mathrm{Arnt}^{+/+}$and $\mathrm{Arnt}^{-/-}$lines were established from $\mathrm{Arnt}^{+/-} \times \mathrm{Arnt}^{+/-}$matings and maintained in an undifferentiated state by culturing on mouse embryonic fibroblasts (MEFs) in the presence of FGF-4 and heparin (Tanaka et al. 1998). Arnt ${ }^{-/-}$TS cells proliferated at a slower rate than $A r n t^{+/+}$TS cells, evidenced by plating equal numbers of cells and counting after $4 \mathrm{~d}$ of culture (Fig. 5A). Hypoxic culture conditions induced further proliferation of $\mathrm{Arnt}^{+/+}$TS cells similar to results obtained using primary human cytotrophoblasts (Genbacev et al. 1997). Furthermore, Arnt ${ }^{-/-}$TS cells cultured under low $\mathrm{O}_{2}$ continued to proliferate at a slower rate in comparison to wild-type cells. These in vitro results appear to be inconsistent with the Ki-67 immunohistochemistry shown in Figure 4. However, Ki-67 antibodies fail to quantitate rates of mitosis in proliferating cells. We conclude that hypoxia promotes trophoblast proliferation and that proliferation is slowed in the absence of ARNT.

\section{Hypoxia induces the spongiotrophoblast cell fate in vitro}

We propose based on in situ hybridization analysis of placental sections that the spongiotrophoblast population is not maintained in the absence of HIF activity. To directly test the role of hypoxia in regulating this placental cell fate, we differentiated TS cells in vitro for $4 \mathrm{~d}$, and total RNA was isolated for Northern blot and RT- 
$H \& E$
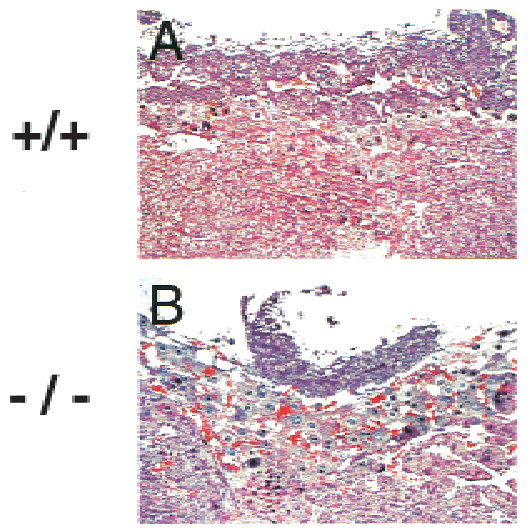

PI.Lac. 1
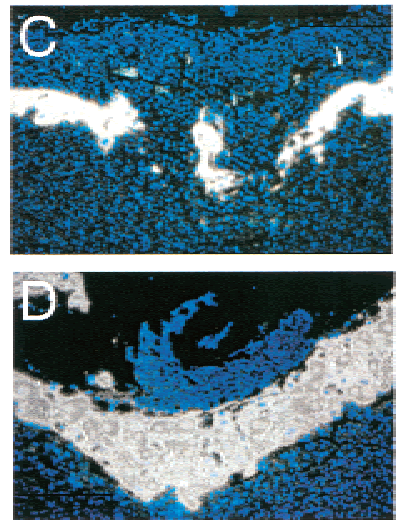

4311
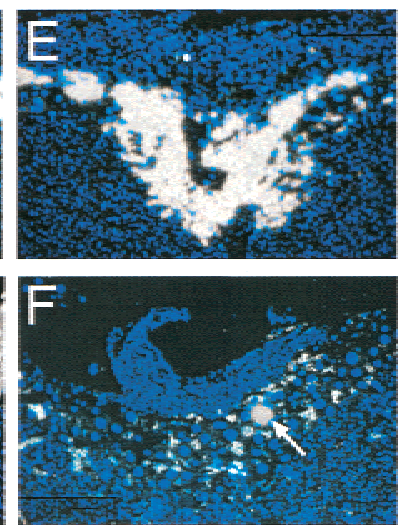
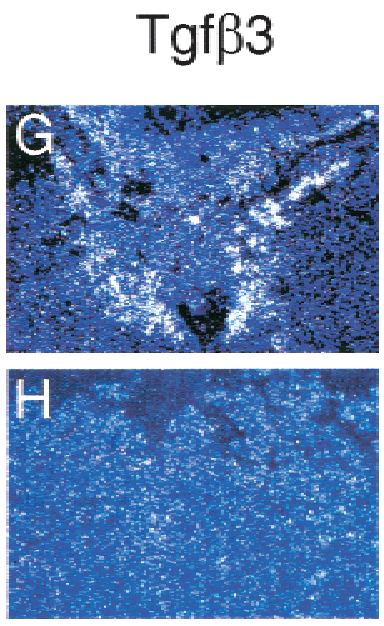

Figure 3. Presence of cells expressing placental lactogen 1 (Pl.Lac.1), 4311, and TGF 33 in E9.5 Arnt $t^{+/+}$and Arnt $t^{-/-}$placentas. $(A-H)$ Sections treated as described for Figure 2. Note the expanded population of giant cells apparent in the sections presented in $B$ and $D$, and the decreased TGF $\beta 3$ expression in $H$. Magnification, 100×.

PCR analyses. Cultures differentiated under normoxia displayed faint but detectable $4311 \mathrm{mRNA}$, in contrast with undifferentiated cultures (Fig. 5B, lanes 1,2). When differentiated under $3 \% \mathrm{O}_{2}$, however, the abundance of 4311 transcripts was enhanced 3.75-fold (Fig. 5B, lanes $3,4)$, suggesting that hypoxia promotes the expansion of $4311^{+}$cells. 4311 transcript abundance was increased 5.25 -fold in TS cells differentiated under $1.5 \% \mathrm{O}_{2}$ (data not shown), suggesting that decreasing $\mathrm{O}_{2}$ gradients can further promote this cell fate. In contrast, differentiated Arnt $^{-/-}$TS cells showed no appreciable 4311 expression by Northern blot assay (Fig. 5B, lanes 5-8), although some expression was detected by RT-PCR analysis (data not shown). Furthermore, Arnt ${ }^{--}$TS cultures showed increased numbers of polyploid giant cells, suggesting an abnormal rate of differentiation to this placental cell fate (data not shown). ERR $\beta 2$ expression was high in undifferentiated TS cells, but extinguished on differentiation as expected (Tanaka et al. 1998). Importantly, this pattern was observed in both $A r n t^{+/+}$and $\mathrm{Arnt}^{t^{--}}$TS cultures. These data indicate that $A_{r n t^{-/}}$TS cells were properly derived but show defects in the adoption of the spongiotrophoblast fate. Other markers, including Mash2, FgfR2, and Oct4 (Tanaka et al. 1998) were appropriately expressed in $A r n t^{+/+}$and Arnt ${ }^{-/-}$cultures (data not shown).

\section{TGFß3 expression in Arnt ${ }^{-/-}$TS cultures is not induced by hypoxia}

Caniggia et al. (2000) have suggested that HIF mediates TGF $\beta 3$ expression in human trophoblasts. However, a role for TGF 33 in murine placental development remains unclear, especially in light of the fact that $\mathrm{Tgf} 3^{-/-}$animals do not show placental defects (Kaartinen et al. 1995; Proetzel et al. 1995). Our in situ data confirm that TGF 33 is down-regulated in the absence of ARNT (see Fig. 3). To determine if TS cells recapitulate these in vivo findings, we extracted RNA from differen- tiated TS cells after $4 \mathrm{~d}$ of normoxic or hypoxic culture. Northern blot analysis was unable to detect a TGF $\beta 3$ signal (data not shown), suggesting that in vitro culture conditions do not completely recapitulate the in vivo environment that promotes TGF $\beta 3$ expression. Using RT-PCR within the linear range, we showed that TGF 33 expression increased in wild-type differentiated TS cell cultures at $3 \% \mathrm{O}_{2}$ (Fig. 5C, lanes 1,2). However, this induction was not detected in Arnt ${ }^{-/-}$cultures (Fig. 5C, lanes 3,4$)$. Therefore, our data reveal that hypoxic TGF $\beta 3$ expression is dependent on ARNT, but TGF $\beta 3$ levels are low in cultured TS cells.

\section{Placental rescue by tetraploid embryo $\Leftrightarrow E S$ cell aggregation}

Abnormal placentation is likely to be the primary cause of the $\mathrm{Arnt}^{-/-}$embryonic lethality, as many placental defects result in death at E8.5-E9.5, and this phenotype is completely penetrant in Arnt $t^{-/-}$animals. Therefore, Arnt ${ }^{-/-}$embryos may be capable of surviving longer if supported by a wild-type placenta. To test this hypothesis, we aggregated $A r n t^{-1-}$ ES cells with wild-type tetraploid green fluorescent protein (GFP)-expressing morulas to generate embryos completely derived from Arnt $^{-/-}$ES cells with wild-type placentas (Fig. 6). An exception to wild-type cells within these placentas are the fetal labyrinthine vessels exclusively derived from embryonic mesodermal precursors and thus of ES cell origin. H\&E staining of E9.7 placental sections obtained from tetraploid embryo $\Leftrightarrow A_{r n t^{+/+}}$and $A r n t^{-/-}$ES cell chimeras indicated no obvious differences between the two. Placentas generated by either Arnt ${ }^{+/+}$or $\mathrm{Arnt}^{-/-}$chimeras were comparable in size and contained abundant numbers of fetal vessels within the labyrinthine layer (see Fig. 7A,B). Thus, formation of the labyrinthine layer requires wild-type trophoblasts whereas ARNT expression within the epiblast component is dispensable, in agreement with the $\mathrm{Arnt}^{-/-}$LacZ chimera experiment 


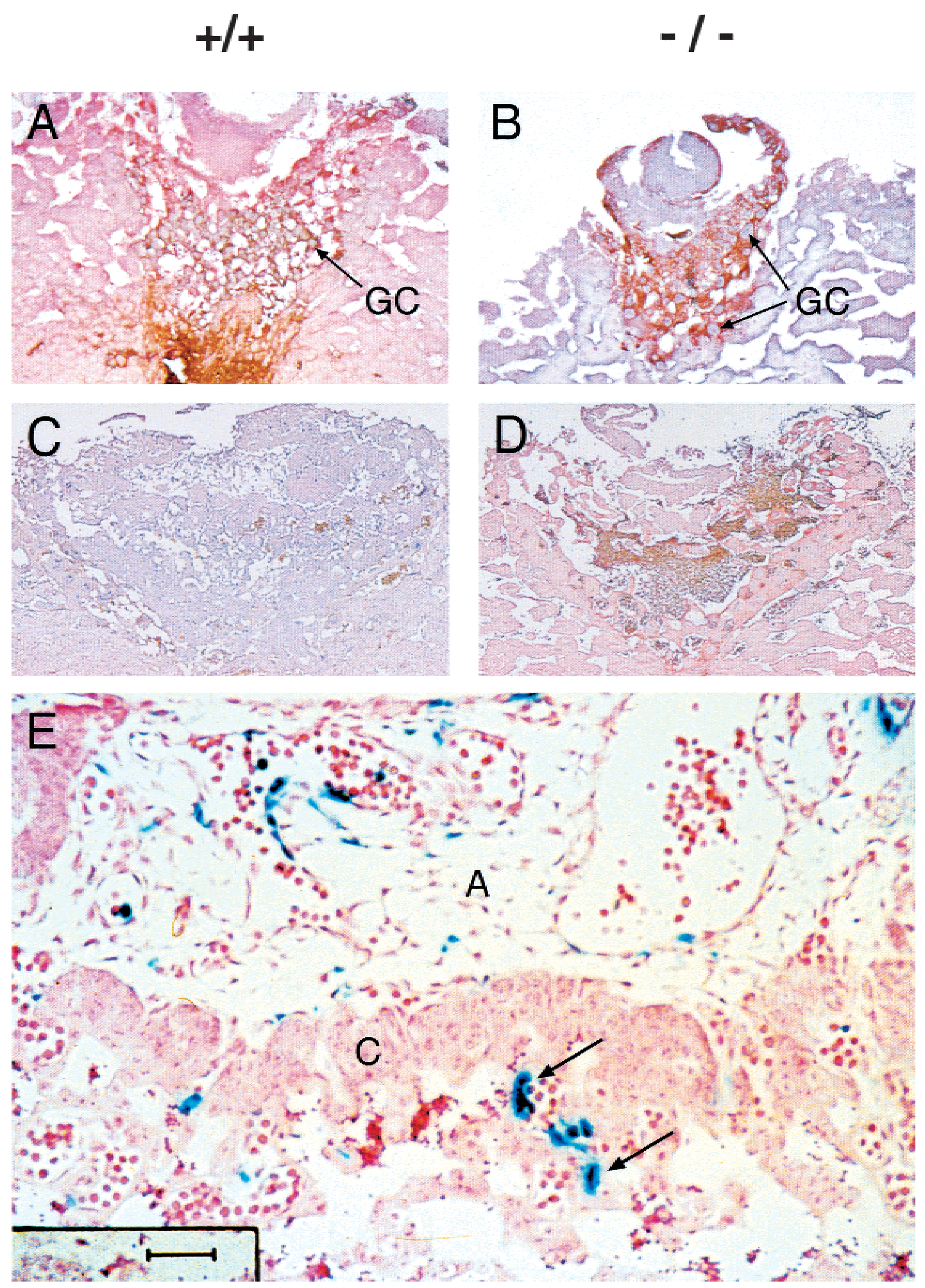

Figure 4. $A r n t^{+/+}$and $A r n t^{-/-}$placental trophoblasts show similar numbers of Ki-67+ proliferating cells at E8.5 $(A, B)$ and E9.5 $(C, D)$ of embryonic development. Paraffin-embedded sections were immunostained with anti-Ki-67 antibodies and counterstained with hematoxylin. The anti-Ki-67 antibody is conjugated with horseradish peroxidase, and Ki- $67^{+}$cells appear reddish brown in $A-D$. The majority of placental cell proliferation has stopped by E9.5, as shown in $C$ and $D$. $(E)$ E9.5 placenta from a chimeric embryo generated with LacZ- tagged Arnt ${ }^{-/-}$ES cells. Arrows indicate $\mathrm{LacZ}^{+} \mathrm{Arnt}^{-/-}$endothelial cells within the labyrinthine layer of the chimeric placenta. Magnification in $A, B: 100 \times ; C, D: 40 \times$; E: 400x. (GC) Giant cells; (A) allantois; (C) chorion. 


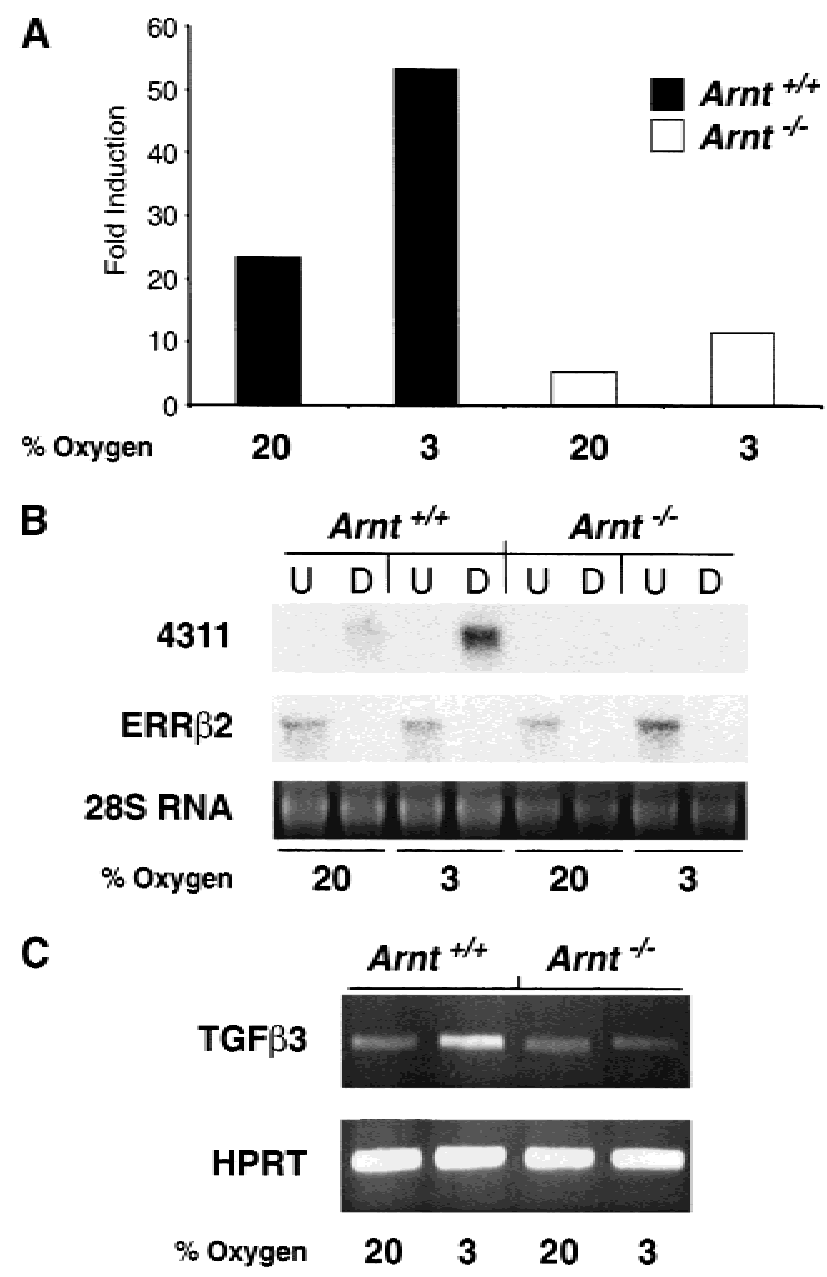

Figure 5. (A) Proliferation of TS cells during culture for $4 \mathrm{~d}$. Arnt $^{-/-}$TS cells show reduced proliferation compared with Arnt $^{+/+}$TS cells, under both normoxic and hypoxic culture conditions. (B) Northern blot analysis of total RNA derived from TS cells cultured for $4 \mathrm{~d}$ in undifferentiating $(\mathrm{U})$ or differentiating (D), as well as normoxic $\left(20 \% \mathrm{O}_{2}\right)$ or hypoxic $\left(3 \% \mathrm{O}_{2}\right)$ conditions. 4311, a marker for spongiotrophoblasts, is detected in differentiated wild-type cells and is elevated four- to fivefold under hypoxia. In contrast, little if any 4311 can be detected in Arnt $^{-/-}$cells. ERR $\beta 2$, a marker specific for undifferentiated TS cells, is down-regulated in all TS lines on differentiation. $(C)$ RT-PCR analysis for TGF 33 . After $4 \mathrm{~d}$, differentiated wild-type TS cells show elevated TGF $\beta 3$ expression at $3 \% \mathrm{O}_{2}$. In contrast, Arnt $^{-1-}$ TS cells did not show any change in TGF 33 expression when cultured under hypoxia.

(see Fig. 4E). These results suggest an endothelial cell extrinsic defect stemming from the lack of factor(s) produced by $\mathrm{Arnt}^{-/-}$placentas responsible for the recruitment of invading endothelium. To determine if the placental vascularization defect was due to impaired placental VEGF expression, we performed in situ hybridization analysis of E8.5 and E9.5 placentas. Although Arnt ${ }^{-/-}$embryos were shown previously to express reduced amounts of VEGF mRNA (Maltepe et al. 1997), Arnt ${ }^{-1-}$ placentas contained wild-type levels of VEGF mRNA (see Table 1), particularly within tropho- blast giant cells known to express high levels of this angiogenic agent (Shweiki et al. 1993; Dumont et al. 1995). Many other angiogenic and/or growth factors were assessed by in situ hybridization analysis with no qualitative differences in expression observed between wildtype and $A r n t^{-/-}$placentas, with the exception of TGF $\beta 3$ (Table 1; Fig. 3). Although ARNT-mediated VEGF expression appears to be important for yolk sac angiogenesis and hematopoiesis, decreased levels of VEGF cannot account for the placental defects in $\mathrm{Arnt}^{-/-}$mice.

\section{Impaired yolk sac vascularization and cardiac development in tetraploid embryo $\Leftrightarrow \mathrm{Arnt}^{-/-}$ES cell chimeras}

E9.7 tetraploid embryo $\Leftrightarrow A r n t^{-/-}$ES cell chimeras appeared indistinguishable from tetraploid embryo $\Leftrightarrow$ $\mathrm{Arnt}^{+/+}$ES cell chimeras on gross examination. In contrast to $\mathrm{Arnt}^{-/-}$embryos derived from $\mathrm{Arnt}^{+/-} \times \mathrm{Arnt}^{+/-}$ crosses, which show developmental delay and smaller size by E9.5, E9.7 $\mathrm{Arnt}^{-/-}$chimeras with appropriate placental vascularization were able to develop to a comparable stage and size (Fig. 6A,C). However, by E10.6 tetraploid embryo $\Leftrightarrow A r n t^{-/-}$ES cell chimeras were significantly smaller, developmentally stunted, and beginning to undergo resorption (Fig. 6G). Both E9.7 and E10.6 tetraploid embryo $\Leftrightarrow A r n t^{-/-}$ES cell chimeras showed severe defects in yolk sac vascularization with no bloodfilled, well-formed vascular structures apparent on gross examination (Fig. 6). This defect in yolk sac vascularization is identical to the defect observed in Arnt ${ }^{-/-}$mice obtained from $A r n t^{+/-} \times \mathrm{Arnt}^{+/-}$crosses despite the fact that the yolk sac endoderm is wild type for ARNT in these chimeras. Closer examination of the yolk sac vasculature indicated the presence of endothelial cells via endothelial-specific lectin immunohistochemistry (Fig. $7 \mathrm{E}, \mathrm{F})$ although at lower numbers than in their wild-type counterparts, within poorly organized vascular channels (Fig. 7D,F). Interestingly, normal VEGF expression in the yolk sac endoderm is sufficient for relatively normal vessel development when the mesoderm is VEGF deficient (Carmeliet et al. 1996). However, the presence of wildtype extraembryonic endoderm surrounding $\mathrm{Arnt}^{-{ }^{-}} \mathrm{ex}-$ traembryonic visceral mesoderm is unable to support yolk sac vascular development suggesting a requirement for factors other than VEGF.

In addition to yolk sac defects, E9.7 tetraploid embryo $\Leftrightarrow A r n t^{-/-}$ES cell chimeras showed hypoplastic tissues within the heart (Fig. 7G,7H). The ventricular myocardium was significantly reduced in size, and the endocardial cushions, which line the atrioventricular (AV) canal and develop into leaflets of the AV valves and septum, were severely underdeveloped. This results in an unusually large AV canal. Regurgitation through a widened AV canal and impaired ventricular function likely result in poor cardiac output and subsequent embryonic demise. Poor forward flow from the malformed heart also may have contributed to the impaired yolk sac vascularization, which depends on hydrostatic pressure and the associated shear forces for vascular modeling. In summary, 
Adelman et al.

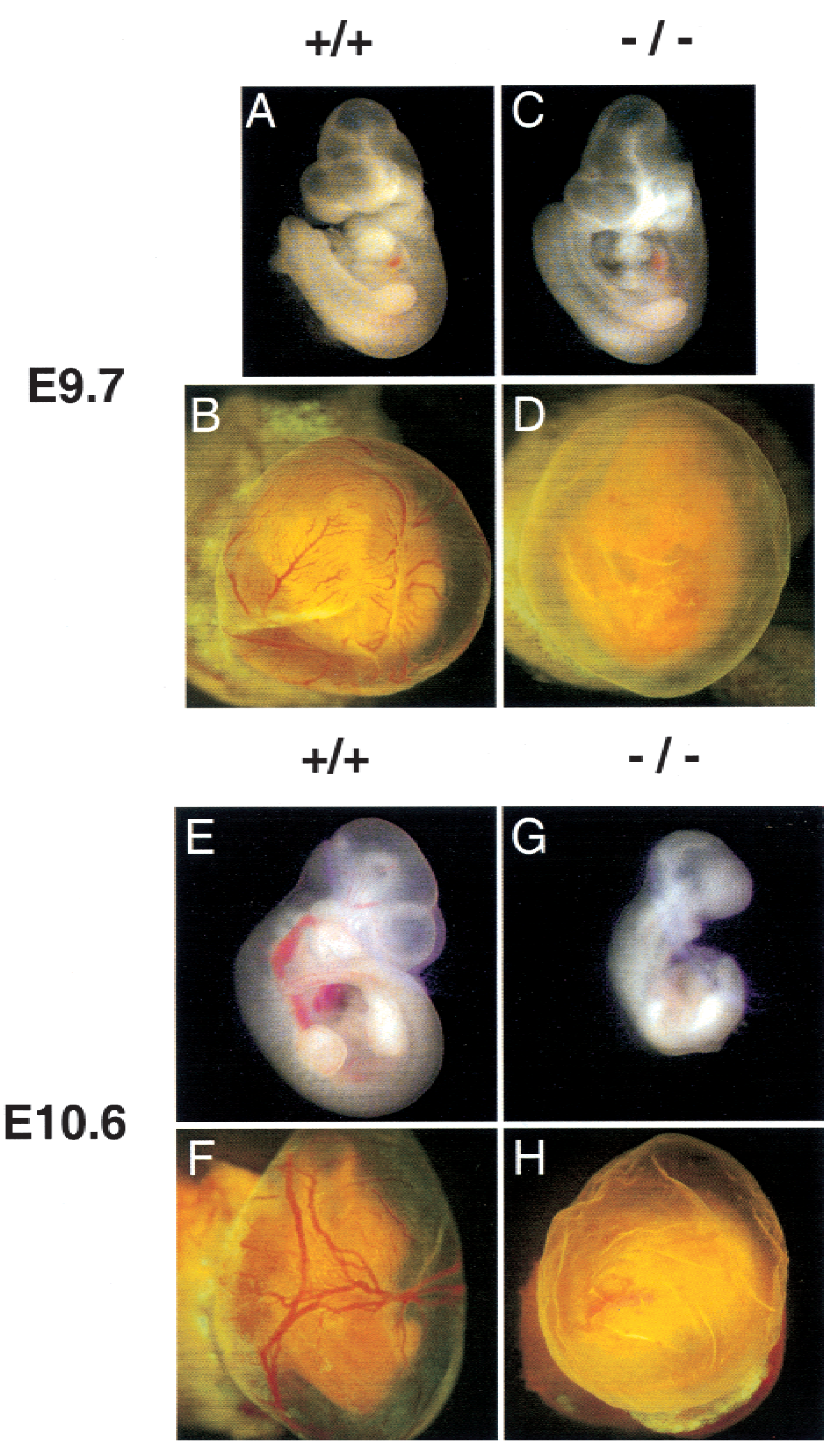

Figure 6. Rescue of $A r n t^{-/-}$placental defects by aggregation of $A r n t^{-/-}$ES cells with tetraploid wild-type morulas that provide functional extraembryonic tissues. $(A-D)$ E9.7 tetraploid embryo $\Leftrightarrow$ ES cell chimeras generated with either $A r n t^{+/+}$ES cells $(A, B)$ or Arnt $^{-1-}$ ES cells $(C, D)$ and green fluorescent protein-tagged wild-type tetraploid embryos. Yolk sacs are shown in $B$ and $D$, whereas embryos dissected free of their yolk sacs are shown in $A$ and C. $(E-H)$ E10.6 chimeras generated with Arnt ${ }^{+/+}$and Arnt ${ }^{-/-}$ES cells. Note the abnormal yolk sac vasculature exhibited by $A r n t^{-1-}$ chimeras at both E9.7 (D) and E10.6 $(H)$. 

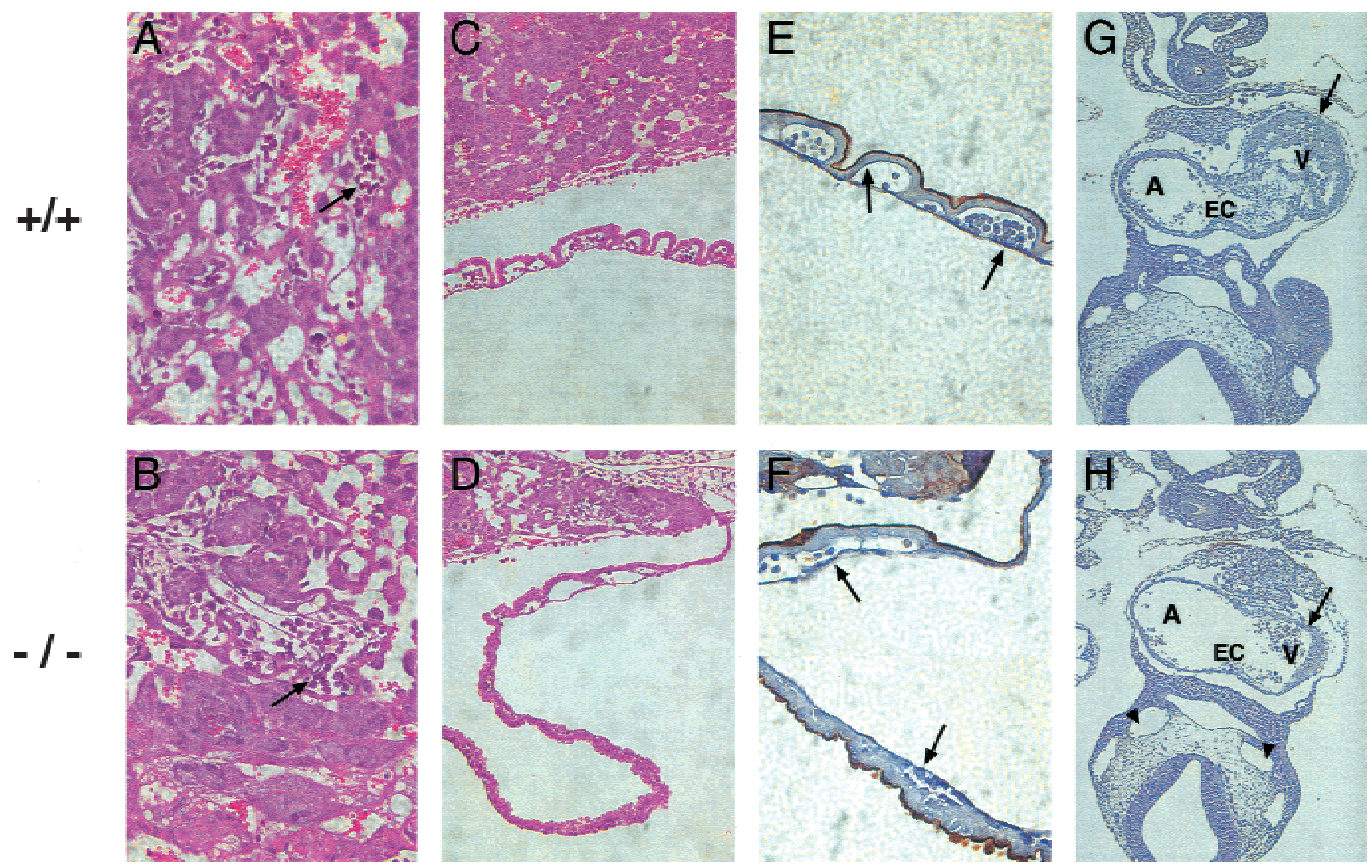

Figure 7. Yolk sac and cardiac defects detected in tetraploid embryo $\Leftrightarrow A r n t^{-/-}$ES cell chimeras. $(A, B)$ Normal labyrinthine layers containing fetal blood vessels (arrows) observed in both $A r n t^{+/+}$and $A r n t^{-/-}$E9.7 chimeric placentas. However, the anomalous yolk sac blood vessel phenotype detected in nonchimeric $A r n t^{-1-}$ animals is preserved in tetraploid embryo $\Leftrightarrow$ ES cell chimeras (although all endodermal derivatives are wild type for the Arnt locus), based on H\&E-stained $(C, D)$ and lectin-stained $(E, F)$ sections. Arrows in $E$ and $F$ indicate endothelial cells within the yolk sac vessels that bind lectin and stain black in this assay. $(G, H)$ Sections obtained from $\mathrm{Arnt}^{+/+}$and $\mathrm{Arnt}^{-/-}$chimeric embryos stained with lectin and counterstained with hematoxylin to show abnormal hearts in the Arnt ${ }^{-/-}$ chimeras. Note the diminished endocardial cushions (EC) and hypoplastic myocardium (arrow) of the Arnt ${ }^{-/-}$heart. Furthermore, vessels such as the dorsal aortae (arrowheads) appear distended, possibly indicating congestive heart failure. (A) Atrium; (EC) endocardial cushion; (V) ventricle. Magnification in $A, B, E, F: 400 \times ; C, D: 200 \times ; G, H: 100 \times$.

embryonic death of the $\mathrm{Arnt}^{-/-}$chimeras at E10.6 is likely due to abnormalities within the vitelline vessels, the heart, or both organs.

\section{Discussion}

We have shown previously that $A r n t^{-/}$embryos show defects in angiogenesis and hematopoiesis (Maltepe et al. 1997; Adelman et al. 1999). Spurred by recent studies describing the role of $\mathrm{O}_{2}$ tension in regulating human placental cell differentiation in vitro (Genbacev et al. 1996, 1997; Caniggia et al. 2000), we characterized placental development in $A r n t^{-/-}$embryos. While these experiments were in progress, Kozak et al. published findings on their Arnt $t^{-/}$mice that also show placental defects (Kozak et al. 1997). The most striking phenotype in our Arnt $^{-1-}$ placentas is a complete loss of the labyrinthine layer. Although $\mathrm{Arnt}^{-/-}$endothelial cells enter the allantois and chorioallantoic fusion takes place, Arnt $^{-/-}$ fetal blood vessels are unable to invade the chorionic plate by E9.5. This is similar to but more severe than the phenotype described in the $\mathrm{Arnt}^{-/-}$mice of Kozak et al., in which $\mathrm{Arnt}^{-/-}$fetal blood vessels invade the chorionic plate but exclusively form large, disorganized endothelial cell-lined cavities (Kozak et al. 1997).

Further analysis of the placental architecture in our $\mathrm{Arnt}^{-1-}$ mice revealed a novel role for ARNT in placental development. E9.5 $\mathrm{Arnt}^{-/-}$placentas contained almost no $4311^{+}$spongiotrophoblast cells whereas the Pl. Lac. $1^{+}$ trophoblast giant cell population was greatly expanded and occupied the space normally containing spongiotrophoblasts. Examination of E8.5 placentas indicated that both cell types were present in similar numbers at this stage. Secondary trophoblast giant cells are derived from diploid trophoblast precursors (Ilgren 1981; Rossant and Tamura-Lis 1981). Our results suggest two possibilities: (1) A bipotent precursor fails to generate sufficient numbers of spongiotrophoblasts in the absence of ARNT and instead produces giant cells via a default developmental pathway, or (2) spongiotrophoblasts themselves differen- 
Table 1. Placental gene expression assayed by in situ hybridization of E8.5 and E9.5 embryos

\begin{tabular}{|c|c|}
\hline Decreased expression & Expressing cells \\
\hline TGF $\beta 3$ & giant cells \\
\hline \multicolumn{2}{|l|}{ Unaltered expression } \\
\hline TGF $\beta 1$ & all trophoblasts \\
\hline Glucose transporter-1 & all trophoblasts \\
\hline Glucose transporter-3 & all trophoblasts \\
\hline Mash 2 & all trophoblasts \\
\hline tissue factor & all trophoblasts \\
\hline $\mathrm{p} 21$ & all trophoblasts \\
\hline Tfeb & labyrinthine trophoblasts \\
\hline PDGF $\beta$ & spongiotrophoblasts \\
\hline PDGFR $\beta$ & spongiotrophoblasts \\
\hline VEGF & giant cells \\
\hline proliferin & giant cells \\
\hline proliferin-related protein & giant cells \\
\hline placental growth factor & giant cells \\
\hline CSF-1R & giant cells \\
\hline Tie-2 & endothelial cells \\
\hline
\end{tabular}

This table takes into account the changes in $4311^{+}$spongiotrophoblast and Pl. Lac. $1^{+}$giant cell numbers in $A r n t^{-/-}$placentas and reflects expression of each listed gene in individual cells.

tiate into giant cells at increased rates in the absence of ARNT. The second possibility is supported by cells that appear to express both 4311 and Pl. Lac. 1 at E8.5 in Arnt $^{-/-}$placentas (see Fig. 2). Furthermore, Arnt ${ }^{-/-}$E8.5 placentas show normal numbers of $4311^{+}$cells that disappear by E9.5 with no increase in $\mathrm{TUNEL}^{+}$apoptotic cells.

The importance of lineage-specific transcription factors in the determination of cell fate has been established in a variety of systems (Driever and Nusslein-Volhard 1988; Struhl et al. 1992). Furthermore, graded expression of transcription factors appears to regulate hematopoietic lineage determination (DeKoter and Singh 2000). Here, we show for the first time that $\mathrm{O}_{2}$ gradients are critical to cell fate determination in vivo. In the absence of ARNT, spongiotrophoblasts are not maintained and precociously differentiate, despite continued Mash2 expression. This requirement for ARNT most likely stems from its ability to mediate the transcriptional response to hypoxia via its interaction with HIF-1 $\alpha$ (or HIF-2 $\alpha$ ). Hypoxia promotes proliferation and inhibits differentiation of human cytotrophoblasts in vitro (Genbacev et al. 1996, 1997; Caniggia et al. 2000). Caniggia et al. suggest that HIF regulates human trophoblast differentiation in part by stimulating TGF 33 expression (Caniggia et al. 2000). It is interesting that $A r n t^{-/}$E9.5 placentas and differentiated TS cultures express less TGF $\beta 3$ (see Figs. $3,5)$. However, the significance of this finding is not clear given that mouse placental development is not impaired in the absence of TGF 33 (Kaartinen et al. 1995; Proetzel et al. 1995). These results suggest that different factors mediate trophoblast differentiation in mice or that TGF 3 is redundant with other regulatory proteins. The placental phenotypes are not secondary to a cardiac defect, as E9.5 $\mathrm{Arnt}^{-/-}$embryos show no discernable cardiac anomalies (Kozak et al. 1997; Maltepe et al. 1997).

Our results definitively establish a role for ARNT in the $\mathrm{O}_{2}$-dependent proliferation and/or differentiation process during murine development. The ability of HIF$1 \alpha$ to interact with the p53 tumor suppressor (An et al. 1998; Ravi et al. 2000) and regulate ES cell proliferation versus apoptosis in response to hypoxia (Carmeliet et al. 1998) also points to this process. Although Hif- $1 \alpha^{-/-}$ mice show early lethality with vascular and mesenchymal cell defects (Iyer et al. 1998; Ryan et al. 1998), a role for HIF- $1 \alpha$ in placental development has not been described in the mouse. HIF- $2 \alpha$, which is also expressed in the placenta (Jain et al. 1998), may be able to compensate in the absence of HIF-1 $\alpha$. Therefore, placentas lacking both HIF- $1 \alpha$ and HIF- $2 \alpha$ would be expected to show a phenotype reminiscent of Arnt $^{-/-}$animals.

Overall, the placental phenotype of $\mathrm{Arnt}^{-/-}$embryos is very similar to the lack of trophoblast-induced vascular adaptation seen in preeclamptic human placentas (Aplin 2000). This is evidenced by a poor labyrinthian layer, which leads to decreased exchange between maternal and fetal circulations and subsequent intrauterine growth retardation. Additionally, Arnt ${ }^{-/-}$placentas show shallow invasion of the maternal deciduum. Poor digestion of maternal extracellular matrix, improper migratory activity, and/or abnormal differentiation of the Arnt $^{-1-}$ trophoblasts may contribute to this defect, resulting in decreased maternal blood flow to the placenta and reduced $\mathrm{O}_{2}$ flow to the embryo. The placenta appears to be reliant on the low $\mathrm{O}_{2}$ environment of the uterus for development. Because HIF-1 $\alpha /$ ARNT heterodimers are master regulators of $\mathrm{O}_{2}$ responsiveness, we believe that $\mathrm{Arnt}^{-/-}$animals provide an important tool for better understanding the early trophoblast-specific events leading to preeclampsia.

The yolk sac vascular defect observed in tetraploid embryo $\Leftrightarrow A r n t^{-/-}$ES cell chimeras was unanticipated. As stated above, the presence of wild-type extraembryonic endoderm surrounding $\mathrm{Arnt}^{-/-}$extraembryonic mesoderm was unable to support vascular development in these yolk sacs. Given that normal VEGF expression in the yolk sac endoderm is sufficient to support vascular development in tetraploid embryo $\Leftrightarrow V E G F^{-/-}$ES cell chimeras (Carmeliet et al. 1996), our results suggest a VEGF-independent role for ARNT in yolk sac vascularization. Nevertheless, vitelline vessels apparently show a cell intrinsic requirement for ARNT that is not rescued by tetraploid chimeras.

Our results describe a novel role for ARNT in cardiac development. Arnt ${ }^{-/-}$hearts in tetraploid chimeras are hypoplastic and show malformed endocardial cushions. Interestingly, Hif-1 $\alpha^{-/-}$embryos also display abnormal hearts (Iyer et al. 1998), confirming a role for HIF-1 in cardiac development. We did not detect a cardiac phenotype in our initial studies on $A r n t^{-/-}$embryos. One explanation for the discrepancy is modifiers present in the C57BL/6 background that are absent in the $129 /$ Sv background of the tetraploid embryo $\Leftrightarrow A r n t^{-/-}$ES cell chimeric embryos. Such effects on embryonic development 
have been described in previous experiments (George et al. 1997; Peng et al. 2000). Distinct genetic backgrounds can also account for differences between our Arnt ${ }^{-/}$embryos and those of Kozak et al.; our R1 ES cell line is derived from chinchilla 129/Sv females $\times$ agouti $129 / \mathrm{Sv}$ CP males, whereas theirs are derived from the $129 / \mathrm{Sv}$ J strain of mice.

In conclusion, we present a novel role for ARNT in placental cell fate determination as well as in cardiac development. Formation of the mammalian placenta allows for $\mathrm{O}_{2}$, nutrient, and waste exchange between fetus and mother and thus is critical for embryonic survival. Insufficient trophoblast invasion of maternal tissue can lead to preeclampsia, which occurs in $7 \%-10 \%$ of pregnancies and remains the major cause of maternal morbidity and mortality in developed countries (Norwitz and Repke 2000; Roberts 2000). Arnt ${ }^{-/-}$mice show a unique placental phenotype and therefore provide an excellent model system for further study of this disease. We propose that the environment within the developing embryo represents a "physiologic" hypoxia that activates HIF and results in proper placental, cardiovascular, and hematopoietic development (Maltepe and Simon 1998). Thus, $\mathrm{O}_{2}$ acts not only as the terminal electron acceptor in mitochondrial oxidative phosphorylation but also as a signal responsible for transcription factor activation. Therefore, the formation of $\mathrm{O}_{2}$ gradients within developing embryos activates hypoxic gene expression in a dose-dependent fashion.

\section{Materials and methods}

\section{Generation of ES cells, chimeras, and mice}

$\mathrm{Arnt}^{+/-}$ES cells were selected in high levels of G418 to produce Arnt $^{-/-}$clones (Adelman et al. 1999), and then Arnt $^{-/-}$cells were electroporated with a plasmid containing both EF1/ $\alpha$ - $\beta$-galactosidase and Hygromycin to generate LacZ expressing clones. Hygromycin transfectants were screened for $\beta$-galactosidase activity before injection into E3.5 blastocysts for chimera analysis at E9.5. Chimerism was assessed by staining embryos and scoring LacZ $^{+}$cells. Arnt $t^{+/+}$and Arnt ${ }^{-/-}$ES cells were aggregated with successfully fused four-cell-staged tetraploid embryos tagged with ubiquitous expression of GFP (Hadjantonakis et al. 1998), as described (Nagy and Rossant 1996). After 26 h of incubation, aggregated embryos that formed blastocysts were transferred to the uterine horn of day 2.5 pseudopregnant CD-1 recipients. Recipients were sacrificed at E9.7 and E10.6 for analysis of embryonic and extraembryonic tissues via histological sections. Embryos completely derived from ES cell were detected by visualizing the exclusive allocation of the tetraploid compartment to extraembryonic membranes by a MAA-02 GFP visualizing light source (BLS Ltd.). Whole-mount photography was made with a CoolScan digital camera attached to a Leica stereo microscope.

\section{Immunohistochemistry}

Formalin-fixed, paraffin-embedded sections were stained with either a mouse monoclonal antibody to Ki-67 (NCL-Ki-67MM1; Novocastra Laboratories) or a biotinylated lectin from Griffonia simplicifolia (B-1205; Vector Labs). Antigen unmasking was performed in each case (H-3300; Vector Labs), and per- oxidase staining was performed with a DAB substrate kit (SK4100; Vector Labs).

\section{TS cell culture}

Trophoblast stem cells were derived as specified (Tanaka et al. 1998). Briefly, E3.5 blastocysts were cultured on MEFs in the presence of FGF-4 and heparin. After multiple passages, cells were genotyped by Southern blot and assayed for the appropriate gene expression profile, especially to ascertain that no inner cell mass derivatives were present (e.g., no Oct4 expression). Differentiating culture conditions involved the removal of MEFs and FGF-4/heparin. Hypoxic culture was performed in an IG750 3 Gas Incubator (Jouan) or an In Vivo 2400 Hypoxic Tissue Culture Hood (Toucan Technologies). Culture media was supplemented with $25 \mathrm{mM}$ HEPES (pH 8.0) for increased buffer capacity during hypoxic culture.

\section{RNA analysis}

Undifferentiated and differentiated TS cells cultured at $20 \%$, $3 \%$, or $1.5 \% \mathrm{O}_{2}$ for $4 \mathrm{~d}$ were washed with PBS and RNA was extracted with TRIzol reagent (Life Technologies) based on the manufacturer's instructions. For in situ hybridization, formalinfixed, paraffin-embedded sections were baked at $55^{\circ} \mathrm{C}$ for $1 \mathrm{~h}$. Sense and antisense probes were generated using T7 or SP6 RNA polymerases incorporating ${ }^{35} \mathrm{~S}$-UTP. After overnight hybridization, sections were washed, dehydrated, and exposed to film. Successful hybridizations were dipped in emulsion and exposed for $7 \mathrm{~d}$, then developed and counterstained with Hoechst 33258 (Sigma). For RT-PCR, complementary DNA was generated from $1 \mathrm{\mu g}$ of total RNA from each sample.

Primers used were as follows: Pl.Lac. 1: $5^{\prime}$ ccactgaagacctgtata ctc, $3^{\prime}$ ggactgcagttcttcgagtc; 4311: 5' caggtacttgagacatgactc, 3' ggcagagatttcttagacaatg; TGF 3 : 5' caaagggctctggtagtcctg, 3' ctt agaggtaattcctttgggg; VEGF: 5' ccatgcagatcatgcggatc, 3' caagt gctcctcgaaggatc; Proliferin: $5^{\prime}$ gtgcaatgaggaatggtcg, $3^{\prime}$ cattctgaa gcatggtgctc; PRP: 5' gatttgcacaagagtacggag, 3' cagagtagcagacat catc; PlGF: 5' cagccaacatcactatgcag, 3' gtccatgtcttgcttcttcc; CSF1R: 5' cctaacaactaccagttctgc, 3' cacggtttttgttggtgtgg; Glut-1: $5^{\prime}$ gtcctatctgagcatcgtgg, $3^{\prime}$ caaggtgaagactacagtgtg; Glut-3: 5' gecttctttgagattggacc , 3' cattggegatctggtcaacc; Tie-2: 5' cgttact cagtaccagctc, 3' ctccgatcacgtcttgaaac; Tfeb: 5' caggctgtcatgcat tatatgc, 3' gcataatgttgtcaatgacatc; Mash2: 5' gaaggtgcaaacgtc cacttc, $3^{\prime}$ ccttactcagcttcttgttgg; Tissue factor: $5^{\prime}$ caagtgcttctc gaccacag, 3' ggtgcacactgtactgcttg; p21: 5' cagatccacagcgatatccag, $3^{\prime}$ ggagtgatagaaatctgtcagg; TGF $\beta 1$ : 5' gaggactccagacagccetgc, $3^{\prime}$ gatgagcgetctctgagatcc; PDGF $\beta$ : 5' ctgcagctccacatgcaaaggact, $3^{\prime}$ tcagagttcctccagtctgtg; PDGFR $\alpha$ : $5^{\prime}$ tcctctgtatcttgtaatctg, $3^{\prime}$ ac tggtcaggagagacatctg; HPRT: 5' cacaggactagaacacctgc, 3' gctggt gaaaaggacctct ; Oct4: 5' ggcgttctctttggaaaggtgttc, $3^{\prime}{ }^{\prime}$ ctcgaacca catccttctct.

\section{Acknowledgments}

We thank Cynthia Clendenin, Min-min Lu, Michele Hadhazy, and Jeremy Lipman for technical assistance; H. Scott Baldwin for helpful discussions; Francine Tucker for secretarial assistance; and Brian Keith and Diana Ramirez for critically reviewing the manuscript. This research was supported by Grant HL63310 from the National Institutes of Health (M.C.S) and the Abramson Family Cancer Research Institute. D.M.A. and E.M. are fellows of the Medical Scientist Training Program at the University of Chicago. M.C.S. is an investigator at the Howard Hughes Medical Institute. 
The publication costs of this article were defrayed in part by payment of page charges. This article must therefore be hereby marked "advertisement" in accordance with 18 USC section 1734 solely to indicate this fact.

\section{Note added in proof}

An additional analysis of $\mathrm{Arnt}^{-/-}$can be found in Developmental Dynamics 219: 526-538 (2000).

\section{References}

Adelman, D.M., Maltepe, E., and Simon, M.C. 1999. Multilineage embryonic hematopoiesis requires hypoxic ARNT activity. Genes \& Dev. 13: 2478-2483.

Akazawa, S., Unterman, T., and Metzger, B.E. 1994. Glucose metabolism in separated embryos and investing membranes during organogenesis in the rat. Metabolism 43: 830-835.

An, W.G., Kanekal, M., Simon, M.C., Maltepe, E., Blagosklonny, M.V., and Neckers, L.M. 1998. Stabilization of wildtype p53 by hypoxia-inducible factor $1 \alpha$. Nature 392: $405-$ 408.

Aplin, J.D. 2000. Hypoxia and human placental development. J. Clin. Invest. 105: 559-560.

Bunn, H.F. and Poyton, R.O. 1996. Oxygen sensing and molecular adaptation to hypoxia. Physiol. Rev. 76: 839-885.

Caniggia, I., Mostachfi, H., Winter, J., Gassmann, M., Lye, S.J., Kuliszewski, M., and Post, M. 2000. Hypoxia-inducible factor- 1 mediates the biological effects of oxygen on human trophoblast differentiation through $\mathrm{TGF} \beta(3)$. J. Clin. Invest. 105: $577-587$.

Carmeliet, P., Ferreira, V., Breir, G., Pollefeyt, S., Kieckens, L., Gertenstein, M., Fahrig, M., Vandenhoeck, A., Harpal, K., Eberhard, C., et al. 1996. Abnormal blood vessel development and lethality in embryos lacking a single VEGF allele. Nature 380: 435-439.

Carmeliet, P., Dor, Y., Herbert, J.M., Fukumura, D., Brusselmans, K., Dewerchin, M., Neeman, M., Bono, F., Abramovitch, R., Maxwell, P., et al. 1998. Role of HIF-1 $\alpha$ in hypoxiamediated apoptosis, cell proliferation and tumour angiogenesis. Nature 394: 485-490.

Cross, J.C., Werb, Z., and Fisher, S.J. 1994. Implantation and the placenta: Key pieces of the development puzzle. Science 266: 1508-1518.

Cross, J.C., Flannery, M.L., Blanar, M.A., Steingrimsson, E., Jenkins, N.A., Copeland, N.G., Rutter, W.J., and Werb, Z. 1995. Hxt encodes a basic helix-loop-helix transcription factor that regulates trophoblast cell development. Development 121: 2513-2523.

DeKoter, R.P. and Singh, H. 2000. Regulation of B lymphocyte and macrophage development by graded expression of PU.1. Science 288: 1439-1441.

Driever, W. and Nusslein-Volhard, C. 1988. The bicoid protein determines position in the Drosophila embryo in a concentration-dependent manner. Cell 54: 95-104.

Dumont, D.J., Fong, G.H., Puri, M.C., Gradwohl, G., Alitalo, K., and Breitman, M.L. 1995. Vascularization of the mouse embryo: A study of flk-1, tek, tie, and vascular endothelial growth factor expression during development. Dev. Dyn. 203: $80-92$.

Fischer, B. and Bavister, B.D. 1993. Oxygen tension in the oviduct and uterus of rhesus monkeys, hamsters and rabbits. $J$. Reprod. Fertil. 99: 673-679.

Genbacev, O., Joslin, R., Damsky, C.H., Polliotti, B.M., and
Fisher, S.J. 1996. Hypoxia alters early gestation human cytotrophoblast differentiation/invasion in vitro and models the placental defects that occur in preeclampsia. J. Clin. Invest. 97: 540-550.

Genbacev, O., Zhou, Y., Ludlow, J.W., and Fisher, S.J. 1997. Regulation of human placental development by oxygen tension. Science 277: 1669-1672.

George, E.L., Baldwin, H.S., and Hynes, R.O. 1997. Fibronectins are essential for heart and blood vessel morphogenesis but are dispensable for initial specification of precursor cells. Blood 90: 3073-3081.

Guillemot, F., Nagy, A., Auerbach, A., Rossant, J., and Joyner, A.L. 1994. Essential role of Mash-2 in extraembryonic development. Nature 371: 333-336.

Guillemot, F., Caspary, T., Tilghman, S.M., Copeland, N.G., Gilbert, D.J., Jenkins, N.A., Anderson, D.J., Joyner, A.L., Rossant, J., and Nagy, A. 1995. Genomic imprinting of Mash2, a mouse gene required for trophoblast development. Nat. Genet. 9: 235-242.

Hadjantonakis, A.K., Gertsenstein, M., Ikawa, M., Okabe, M., and Nagy, A. 1998. Generating green fluorescent mice by germline transmission of green fluorescent ES cells. Mech. Dev. 76: 79-90.

Ilgren, E.B. 1981. On the control of the trophoblastic giant-cell transformation in the mouse: Homotypic cellular interactions and polyploidy. J. Embryol. Exp. Morphol. 62: 183-202.

Iyer, N.V., Kotch, L.E., Agani, F., Leung, S.W., Laughner, E., Wenger, R.H., Gassmann, M., Gearhart, J.D., Lawler, A.M., Yu, A.Y., et al. 1998. Cellular and developmental control of O2 homeostasis by hypoxia- inducible factor $1 \alpha$. Genes \& Dev. 12: 149-162.

Jain, S., Maltepe, E., Lu, M.M., Simon, C., and Bradfield, C.A. 1998. Expression of ARNT, ARNT2, HIF1 $\alpha, \mathrm{HIF} 2 \alpha$ and Ah receptor mRNAs in the developing mouse. Mech. Dev. 73: $117-123$.

Janatpour, M.J., McMaster, M.T., Genbacev, O., Zhou, Y., Dong, J., Cross, J.C., Israel, M.A., and Fisher, S.J. 2000. Id-2 regulates critical aspects of human cytotrophoblast differentiation, invasion and migration. Development 127: 549-558.

Kaartinen, V., Voncken, J.W., Shuler, C., Warburton, D., Bu, D., Heisterkamp, N., and Groffen, J. 1995. Abnormal lung development and cleft palate in mice lacking TGF- $\beta 3$ indicates defects of epithelial-mesenchymal interaction. Nat. Genet. 11: 415-421.

Kozak, K.R., Abbott, B., and Hankinson, O. 1997. ARNT-deficient mice and placental differentiation. Dev. Biol. 191: 297305.

Kraut, N., Snider, L., Chen, C.M., Tapscott, S.J., and Groudine, M. 1998. Requirement of the mouse I-mfa gene for placental development and skeletal patterning. EMBO J. 17:62766288.

Maltepe, E. and Simon, M.C. 1998. Oxygen, genes, and development: An analysis of the role of hypoxic gene regulation during murine vascular development. J. Mol. Med. 76: 391401.

Maltepe, E., Schmidt, J.V., Baunoch, D., Bradfield, C.A., and Simon, M.C. 1997. Abnormal angiogenesis and responses to glucose and oxygen deprivation in mice lacking the protein ARNT. Nature 386: 403-407.

Mitchell, J.A. and Yochim, J.M. 1968. Intrauterine oxygen tension during the estrous cycle in the rat: Its relation to uterine respiration and vascular activity. Endocrinology 83: 701705 .

Nagy, A. and Rossant, J. 1996. Targeted mutagenesis: Analysis of phenotype without germ line transmission. J. Clin. Invest. 97: 1360-1365. 
Nagy, A., Gocza, E., Diaz, E.M., Prideaux, V.R., Ivanyi, E., Markkula, M., and Rossant, J. 1990. Embryonic stem cells alone are able to support fetal development in the mouse. Development 110: 815-821.

Norwitz, E.R. and Repke, J.T. 2000. Preeclampsia prevention and management. J. Soc. Gynecol. Invest. 7: 21-36.

Peng, J., Zhang, L., Drysdale, L., and Fong, G.H. 2000. The transcription factor EPAS-1/hypoxia-inducible factor $2 \alpha$ plays an important role in vascular remodeling. Proc. Natl. Acad. Sci. 97: 8386-8391.

Phillips, P.G., Birnby, L.M., and Narendran, A. 1995. Hypoxia induces capillary network formation in cultured bovine pulmonary microvessel endothelial cells. Am. J. Physiol. 268: L789-L800.

Proetzel, G., Pawlowski, S.A., Wiles, M.V., Yin, M., Boivin, G.P., Howles, P.N., Ding, J., Ferguson, M.W., and Doetschman, T. 1995. Transforming growth factor- $\beta 3$ is required for secondary palate fusion. Nat. Genet. 11: 409-414.

Ravi, R., Mookerjee, B., Bhujwalla, Z.M., Sutter, C.H., Artemov, D., Zeng, Q., Dillehay, L.E., Madan, A., Semenza, G.L., and Bedi, A. 2000. Regulation of tumor angiogenesis by p53-induced degradation of hypoxia- inducible factor $1 \alpha$. Genes \& Dev. 14: 34-44.

Riley, P., Anson-Cartwright, L., and Cross, J.C. 1998. The Hand 1 bHLH transcription factor is essential for placentation and cardiac morphogenesis. Nat. Genet. 18: 271-275.

Roberts, J.M. 2000. Preeclampsia: What we know and what we do not know. Semin. Perinatol. 24: 24-28.

Rossant, J. and Tamura-Lis, W. 1981. Effect of culture conditions on diploid to giant-cell transformation in postimplantation mouse trophoblast. J. Embryol. Exp. Morphol. 62: 217-227.

Ryan, H.E., Lo, J., and Johnson, R.S. 1998. HIF-1a is required for solid tumor formation and embryonic vascularization. EMBO J. 17: 3005-3015.

Shweiki, D., Itin, A., Neufeld, G., Gitay-Goren, H., and Keshet, E. 1993. Patterns of expression of vascular endothelial growth factor (VEGF) and VEGF receptors in mice suggest a role in hormonally regulated angiogenesis. J. Clin. Invest. 91: 2235-2243.

Struhl, G., Johnston, P., and Lawrence, P.A. 1992. Control of Drosophila body pattern by the hunchback morphogen gradient. Cell 69: 237-249.

Sun, X.H., Copeland, N.G., Jenkins, N.A., and Baltimore, D. 1991. Id proteins Id 1 and Id2 selectively inhibit DNA binding by one class of helix-loop-helix proteins. Mol. Cell. Biol. 11: 5603-5611.

Tanaka, M., Gertsenstein, M., Rossant, J., and Nagy, A. 1997. Mash2 acts cell autonomously in mouse spongiotrophoblast development. Dev. Biol. 190: 55-65.

Tanaka, S., Kunath, T., Hadjantonakis, A.K., Nagy, A., and Rossant, J. 1998. Promotion of trophoblast stem cell proliferation by FGF4. Science 282: 2072-2075.

Wenger, R.H. and Gassmann, M. 1997. Oxygen(es) and the hypoxia-inducible factor-1. Biol. Chem. 378: 609-616. 


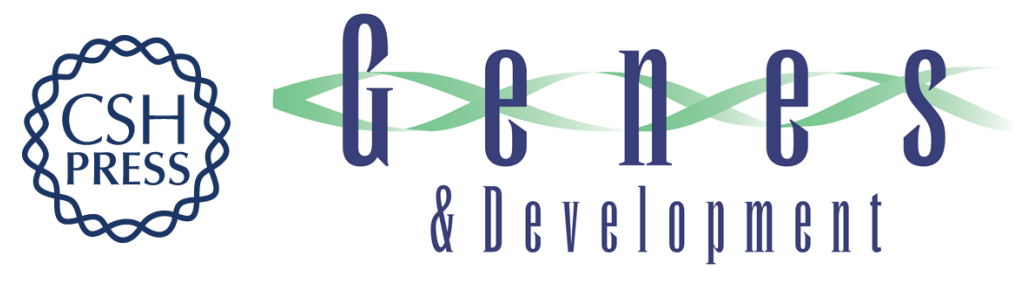

\section{Placental cell fates are regulated in vivo by HIF-mediated hypoxia responses}

David M. Adelman, Marina Gertsenstein, Andras Nagy, et al.

Genes Dev. 2000, 14:

Access the most recent version at doi:10.1101/gad.853700a

References

This article cites 45 articles, 16 of which can be accessed free at: http://genesdev.cshlp.org/content/14/24/3191.full.html\#ref-list-1

\section{License}

Email Alerting

Receive free email alerts when new articles cite this article - sign up in the box at the top Service right corner of the article or click here.

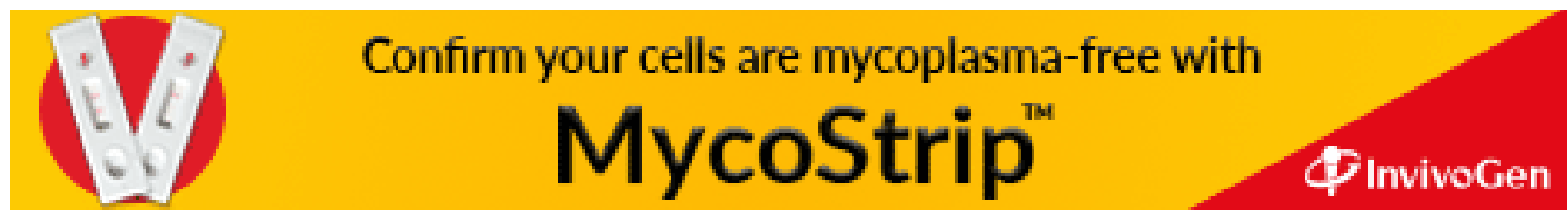

